\title{
MIGRAÇÃO, UMA RESPONSABILIDADE COMPARTILHADA
}

\author{
MIGRACIÓN, UNA RESPONSABILIDAD COMPARTIDA
}

MIGRATION, THE RESPONSABILITY WE SHARE

ENTREVISTA - Dra. Silvia E. Giorguli Saucedo, Presidenta de El Colegio de México.

São Paulo, 12 de junho de 2018

Ernesto Morales Bautista ${ }^{1}$

Universidad Autónoma de la Ciudad de México, CDMX, México.

Gabriel Brito Nunes ${ }^{2}$

Universidade de São Paulo, São Paulo, Brasil.

Lucilene Cury ${ }^{3}$

Universidade de São Paulo, São Paulo, Brasil.

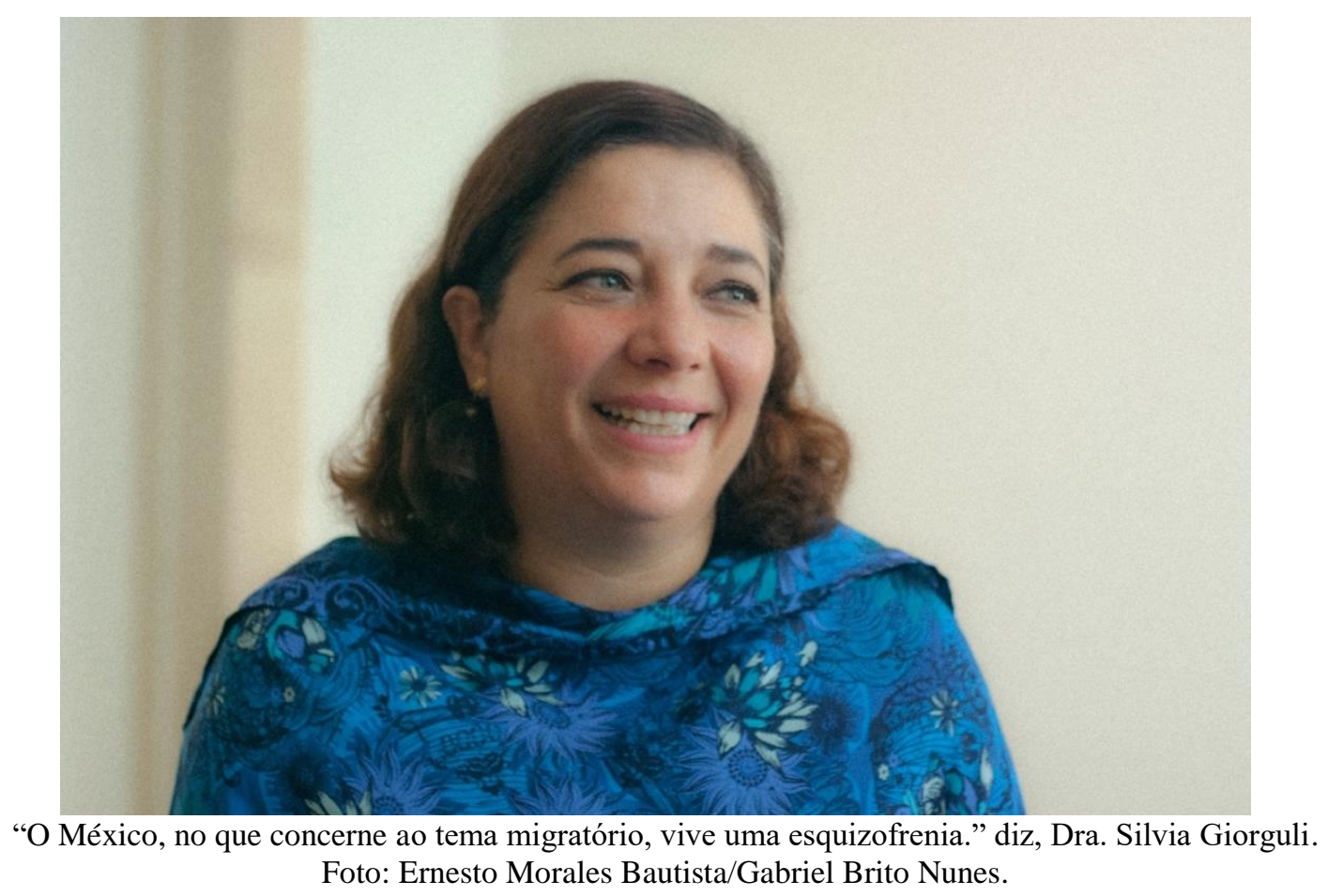

\footnotetext{
${ }^{1}$ Artista e estudante do curso de Comunicação e Cultura da Universidad Autónoma de la Ciudad de México, UACM, onde desenvolve pesquisa sobre Migração e Fronteiras aplicadas à arte e linguagens digitais. Email: moralbaut@gmail.com.

${ }^{2}$ Artista e estudante do Programa de Pós-Graduação Integração da América Latina, PROLAM, Universidade de São Paulo, USP, onde desenvolve pesquisa sobre práticas autônomas de performance art do México y Cuba. Email: gabrielbritonunes@gmail.com.

${ }^{3}$ Professora Associada na Escola de Comunicações e Artes, ECA, da Universidade de São Paulo, USP. E-mail: lucilene@usp.br.
} 
Ernesto Morales Bautista

Gabriel Brito Nunes

Lucilene Cury
Cadernos Prolam/USP, v. 17, n. 32, p. 6-18, jan./jun. 2018

DOI: 10.11606/issn.1676-6288.prolam.2018.148830

A professora e pesquisadora do Centro de Estudos Demográficos, Urbanos e Ambientais, CEDUA, e atual presidenta de El Colegio de México, nos recebeu para uma entrevista durante sua estada em São Paulo, na ocasião de dois encontros, organizados pelo Instituto de Estudos Avançados da Universidade de São Paulo, que debateram os efeitos da migração e o bônus demográfico na América Latina.

Além de falar sobre o tema de sua principal linha de pesquisa - a migração internacional do México aos Estados Unidos - a Dra. Silvia Giorguli nos compartilhou seus conhecimentos e visões sobre os impactos da migração na educação de crianças e jovens, e a migração centroamericana. Resultado de uma pesquisa que se estende por mais de duas décadas, a formação acadêmica e profissional da Dra. Silvia Giorguli tem se desenvolvido em um constante diálogo entre ambos os lados da fronteira México-Estados Unidos. Ela afirma que, "no México, todos temos família que migraram", e nos conta que seus filhos nasceram durante seus estudos no exterior e fazem parte do grupo denominado "the population we share" (a população que compartilhamos), que possui dupla nacionalidade e direitos políticos de ambos os lados. Uma característica que, ela insiste, pode nortear possíveis maneiras de abordagem do presente cenário da migração em todo o mundo.

Profa. Lucilene Cury - Os imigrantes centro-americanos atravessam México para chegar aos Estados Unidos. Por que não permanecer no México? Que tipo de medidas são tomadas para possibilitar a permanência desses migrantes em território mexicano? Há políticas públicas nesse sentido?

Dra. Silvia Giorguli - O México, no que concerne ao tema migratório, vive uma esquizofrenia. Isso por que, há muito tempo, o México tem uma política muito assertiva da defesa dos mexicanos no exterior: mais de cinquenta consulados nos Estados Unidos, associações com redes de advogados e organizações da sociedade civil, e toda uma série de estratégias de apoio para os mexicanos no exterior. O México é, hoje, um dos responsáveis, ao lado do governo da Suíça, por 
Ernesto Morales Bautista

Gabriel Brito Nunes

Lucilene Cury
Cadernos Prolam/USP, v. 17, n. 32, p. 6-18, jan./jun. 2018

DOI: 10.11606/issn.1676-6288.prolam.2018.148830

convocar o Pacto Mundial para la Migración 4 . O México tem toda uma objetividade a nível internacional em relação aos direitos dos migrantes e, quando se olha para dentro, temos grandes vazios, grandes dívidas com os migrantes. É uma falta de congruência, considerando o que se projeta sobre a migração para fora - quando se fala de mexicanos no exterior - em relação ao que está acontecendo dentro. É uma incongruência que passa por muitas coisas: passa pelos marcos normativos; pelo reconhecimento da discriminação e o maltrato que existe ao que é diferente, nesse caso, ao migrante centro-americano; por uma incapacidade das autoridades migratórias para atender a migração centro-americana; e por uma falta de clareza com relação aos objetivos da política de migração.

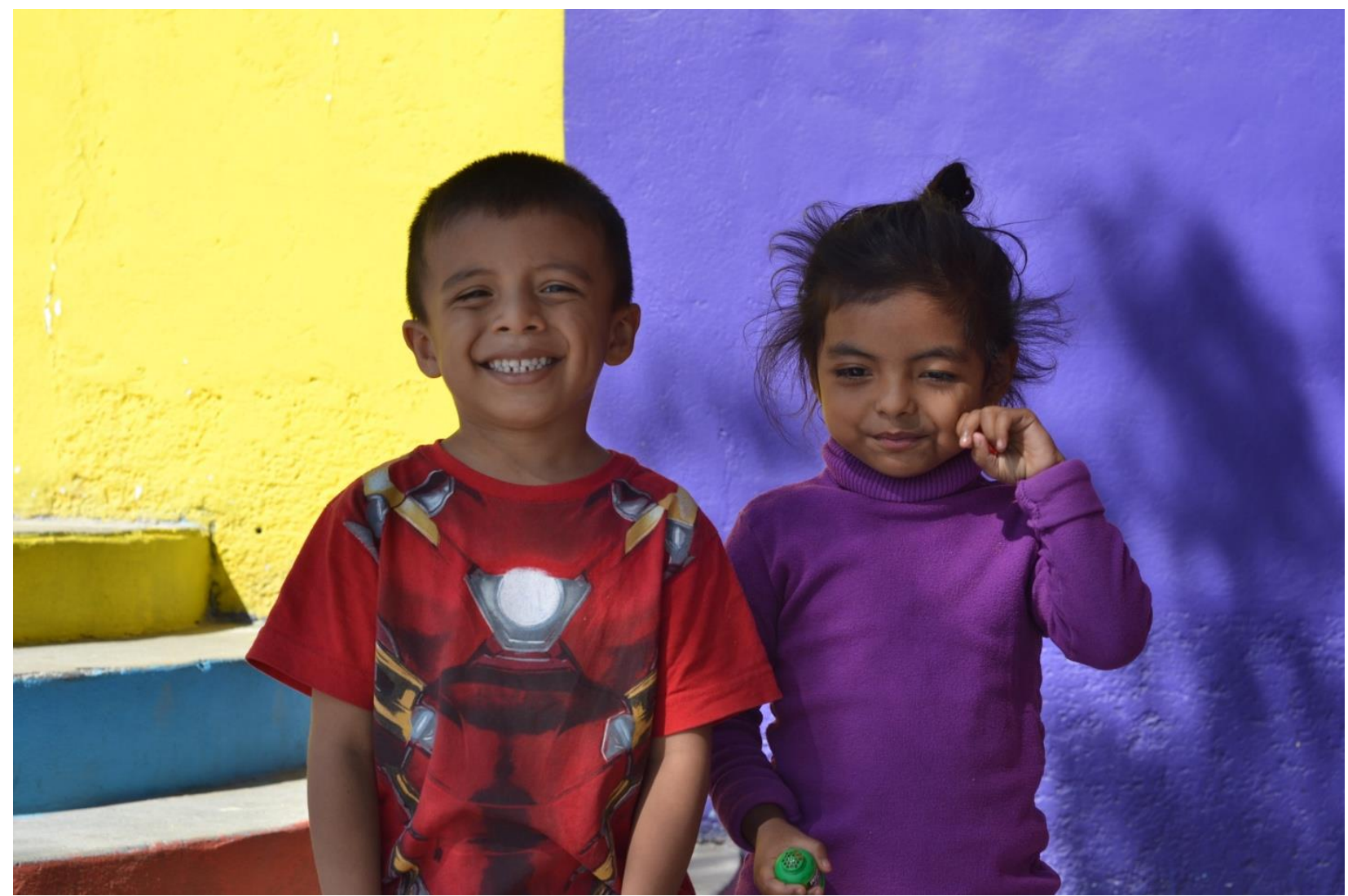

Crianças salvadorenhas que acompanhavam seus pais, ao atravessar o território mexicano do sul ao norte, cujas famílias se encontravam na Casa del Migrante de Saltillo a espera de uma resposta a seu pedido de asilo à Comisión Mexicana de Ayuda a Refugiados, COMAR. Abril de 2017. Foto: Ernesto Morales Bautista/Gabriel Brito Nunes.

\footnotetext{
${ }^{4}$ O Pacto Mundial para la Migración é o primeiro grande acordo multilateral, assinado por todos os Estados-membros da Organização das Nações Unidas com exceção dos Estados Unidos, que tem o objetivo de criar uma série de compromissos para expandir internacionalmente as vias legais e os direitos do migrante.
} 
Ernesto Morales Bautista

Gabriel Brito Nunes

Lucilene Cury
Cadernos Prolam/USP, v. 17, n. 32, p. 6-18, jan./jun. 2018

DOI: $10.11606 /$ issn.1676-6288.prolam.2018.148830

Paradoxalmente, o número de imigrantes no México é baixíssimo, desconsiderando os que nasceram nos EUA. Ou seja, a maior parte dos imigrantes que vive no México vêm dos EUA. De um milhão de imigrantes que existe no México, setecentos e cinquenta mil nasceram nos EUA. E os duzentos e cinquenta mil restantes, que para um país de mais de cento e vinte milhões não significa muito, sofrem um maltrato tremendo que se reproduz também para os migrantes em trânsito.

Em 2011, o México promulgou uma nova lei de migração que era enfocada nos direitos humanos. Em 2012, publicou um programa especial de migração que era muito ambicioso com a ideia de integrar os migrantes que decidiam permanecer no México, de lhes dar acesso à saúde, à educação, de regularizar sua permanência pelo tempo que estivessem no México e, com isso, atender, de alguma maneira, ao tema dos direitos humanos dos migrantes centro-americanos em trânsito e dos que ficam. Mas o que procedeu em realidade, nesses sete anos desde que entrou em vigor essa lei, foi uma contradição do governo mexicano, por que se dispõe de um novo marco legal que apoia os Direitos Humanos e, ao mesmo tempo, realizam-se programas que criminalizam o migrante em trânsito. E, aí, há muitos casos de violação aos Direitos Humanos tanto por conta do crime organizado, como pelos próprios agentes da polícia migratória.

\section{Ernesto Morales Bautista - Como na fronteira ao sul...}

S. G. - Desde a fronteira ao sul e em trânsito também, pelos estados que os migrantes centroamericanos vão cruzando, como Oaxaca. Alguns passam por Tabasco e pelo restante do território mexicano. Creio que uma das coisas que mais complica esse cenário é sua sobreposição com as rotas do crime organizado. Onde há mais insegurança, mais violência, mais vulnerabilidade dos migrantes e pouca efetividade do Estado. Não sei se falta vontade política, mas efetividade política, sim.

L. C. - Como pesquisadora, a senhora integrou o Proyecto Sobre Migración Mexicana ${ }^{5}$ em 2015 e acompanhou de perto a transição do mandato do ex-presidente Barack Obama ao atual governo

\footnotetext{
5 O Proyecto Sobre Migración Mexicana, MMP, é um esforço multidisciplinar que gera dados públicos sobre as características e o comportamento dos migrantes mexicanos. Desde sua criação, em 1982, por um grupo interdisciplinar de pesquisadores do México e dos Estados Unidos, com o objetivo de ampliar e melhorar a compreensão do processo de migração mexicana para os Estados Unidos, o $M M P$ tem reunido informações sociais, econômicas e demográficas
} 
Ernesto Morales Bautista

Gabriel Brito Nunes

Lucilene Cury
Cadernos Prolam/USP, v. 17, n. 32, p. 6-18, jan./jun. 2018

DOI: 10.11606/issn.1676-6288.prolam.2018.148830

estadunidense de Donald Trump. Que mudanças têm ocorrido desde então? Pensamos, por exemplo, na tentativa de suspensão da Acción Diferida para los Llegados en la Infancia, DACA ${ }^{6}$.

S. G. - O que estamos vendo nesse momento de vulnerabilidade dos migrantes com Trump não decorre somente de seu governo. Um personagem como Trump provoca crises em um modelo de gestão migratória complexo, o estadunidense. O que acontece? Como chegamos aí? Nos EUA, existem doze milhões de mexicanos, ou melhor, onze ponto seis milhões. Desse número, cerca da metade é indocumentada. Como se chegou a essa população de indocumentados mexicanos, além de uma percentagem de outras nacionalidades? Nessa situação, o caso mexicano apresenta dois elementos: nos anos oitenta, houve uma mudança na política estadunidense que se tornou mais orientada ao controle fronteiriço e foi intensificada nos anos noventa, quando começaram os muros, durante a Operación Guardián ${ }^{7}$, e uma série de operações em diferentes pontos da fronteira com o propósito de controlar mais a travessia. E o que dizem é que isso, mais do que fechar a porta de entrada, fechou a porta de saída. Entre 1997 e 2005, existiu a maior saída de mexicanos em direção aos EUA. Em 2000 e 2005, a estimativa de mexicanos migrados por ano aos EUA foi quase de setecentos mil. O padrão de adultos que regressavam - homens e mulheres que trabalhavam e voltavam - se rompe e se cria este padrão familiar. Então, existe essa situação do migrante que não pode regressar e manda trazer a esposa e os filhos. Aquelas crianças que entraram indocumentadas são agora os chamados dreamers. É um processo de acumulação que se tem formado por mais de uma década e que leva a essas situações tão contraditórias de famílias em que um filho nasceu lá e é, portanto, estadunidense - mas o irmão entrou indocumentado aos dois anos de idade. Assim, esse irmão é indocumentado, ainda que aos vinte e cinco anos de idade vivendo nos EUA. Além dos pais que também são indocumentados. Então, dentro de uma mesma família, há uma série de situações de vulnerabilidade: um problema de solução e custo altos com os quais Obama não pôde

sobre o processo de migração entre os dois países. As informações coletadas estão sendo compiladas em um extenso banco de dados cujo uso é aberto ao público por meio da página web: 〈http://mmp.opr.princeton.edu/home-es.aspx〉. ${ }^{6}$ DACA é a sigla em inglês do programa Deferred Action for Children Arrivals, que concede autorização para residir, trabalhar e dirigir nos EUA aos migrantes que entraram no país indocumentados quando crianças. Essa medida evita a deportação imediata, mas não garante a residência permanente ou cidadania futura. Seu decreto foi firmado pelo expresidente estadunidense Barack Obama em junho de 2012 para contornar a dificuldade de aprovar no Congresso a lei Dream - Development, Relief and Education for Alien Minors Act - que deu origem à expressão dreamers, utilizada para designar os imigrantes levados quando crianças para os EUA.

${ }^{7}$ O muro fronteiriço Estados Unidos-México tem o objetivo de impedir a migração indocumentada do México para os EUA. Sua construção se iniciou em 1994, no governo de Bill Clinton, durante o programa de luta contra a imigração conhecido como Operación Guardián. 
Ernesto Morales Bautista

Gabriel Brito Nunes

Lucilene Cury
Cadernos Prolam/USP, v. 17, n. 32, p. 6-18, jan./jun. 2018

DOI: 10.11606/issn.1676-6288.prolam.2018.148830

ou não quis arcar. O que Obama acabou fazendo foi este programa chamado $D A C A$, como uma forma de apoiar. Há toda uma discussão que começou depois de 2001 nos EUA sobre o processo de criminalização do migrante. O migrante indocumentado é como um criminoso, é ilegal, não está cumprindo a lei.

L. C. - Algo que aconteceu em todo o mundo...

S. G. - Sim, mas os EUA se movem nessa época às vezes com mais e em outras, com menos tolerância, dependo também dos ciclos econômicos. Esta é uma época de muita intolerância que se foi criando desde a década passada. Ainda assim, sempre se falou desse grupo de jovens levados por seus pais e que não podiam ser culpados. Para mim, é muito significativo que, nem sequer sobre a forma de legalizar ou regularizar a situação dessa camada populacional, o governo estadunidense consegue chegar a um acordo. Em determinados períodos, surgem iniciativas nos EUA para regularizar os jovens dreamers: os que chegaram antes dos 16 anos, os que não têm antecedentes criminais, que finalizaram a educação pré-universitária, que não saíram do país nesse tempo. No que concerne a esse grupo, o máximo que Obama pôde fazer foi usar o poder presidencial, uma ação executiva para esse programa. Mas que também compreendeu deixá-los em uma vulnerabilidade dependendo de quem fosse eleito. Se houvesse agora um governo democrático - como Hillary Clinton - o programa certamente estaria vigente e, talvez, não posso afirmar com toda certeza, teria buscado uma forma de regularização definitiva.

Gabriel Brito Nunes - Uma regularização definitiva para setecentos e cinquenta mil jovens migrantes indocumentados entre dezesseis e trinta e um anos de idade?

S. G. - Mas esses são somente os que foram acolhidos, por que, quando Obama publica o programa, são acolhidos um certo número de jovens, cerca de oitocentos mil. No entanto, há por volta de três milhões de mexicanos e não mexicanos de todas as nacionalidades que poderiam pertencer ao $D A C A$. Nem todos foram acolhidos pelo programa: alguns por que não cumprem os requisitos de haver terminado o curso pré-universitário. 
Ernesto Morales Bautista

Gabriel Brito Nunes

Lucilene Cury
Cadernos Prolam/USP, v. 17, n. 32, p. 6-18, jan./jun. 2018

DOI: $10.11606 /$ issn.1676-6288.prolam.2018.148830

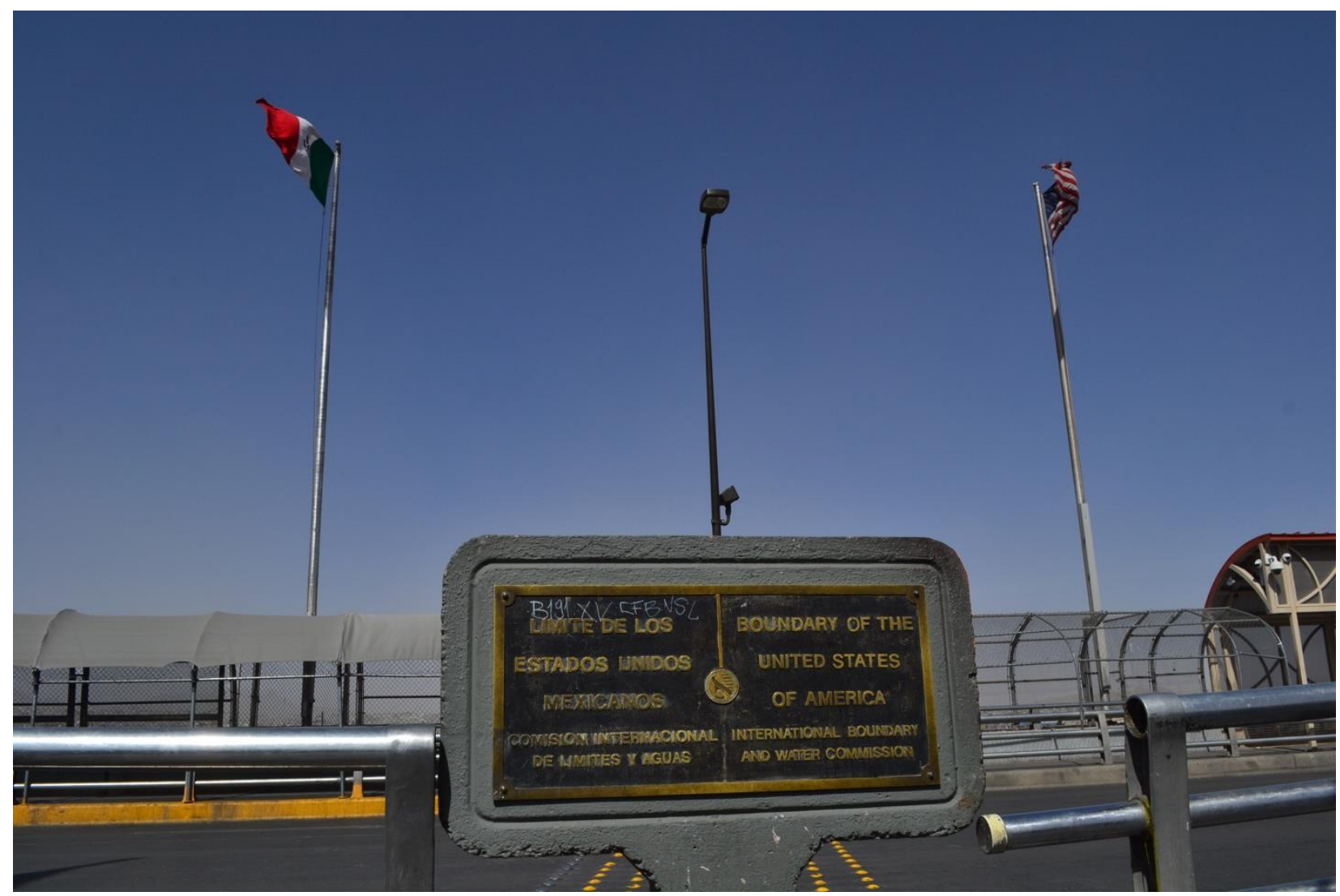

Fronteira México-EUA sobre a Puente del Paso. Abril de 2017. Foto: Ernesto Morales Bautista/Gabriel Brito Nunes.

Há outra coisa: também há jovens que desconfiam por que dizem, “então eu entro no programa, sabem quem eu sou, onde vivo, o que faço - e minha família também é indocumentada - e o que acontece se o programa não seguir." Nesse momento, o programa segue apesar de Trump. Claro que segue sob algumas condições: 1) não foi estendido; 2) Trump já queria dar um fim ao programa, mas, por conta de ordens judiciais de juízes federais, isso não tem sido possível. De qualquer maneira, há uma questão: o programa era por três anos; você dá entrada nos papéis; a ideia é que se renove depois desse período. Aqueles cujos três anos já estão terminando se encontram em um limbo por que, embora o programa não tenha sido cancelado, seu período de vigência já expirou. Trump deu até maio para que as coisas fossem solucionadas na House of Representatives. Nada se resolveu. Então, eles se encontram em uma vulnerabilidade, em um limbo.

G. B. N. - Há um risco, portanto, que a grande maioria desses jovens - setenta e oito por cento de mexicanos, segundo estimativas - regresse ao México? 
Ernesto Morales Bautista

Gabriel Brito Nunes

Lucilene Cury
Cadernos Prolam/USP, v. 17, n. 32, p. 6-18, jan./jun. 2018

DOI: 10.11606/issn.1676-6288.prolam.2018.148830

S. G. - A migração mexicana aos EUA existe há cem anos. Nesses cem anos, sempre existiu o retorno. Sempre tem sido uma migração de ida e vinda. O que faz o retorno de hoje diferente daquele de dez anos atrás? Primeiramente, há mais gente regressando que antes. Somente entre 2005 e 2010, período que coincide com a crise nos EUA, um milhão de mexicanos regressou. Além disso, eles não regressaram sós, vieram com suas famílias. É muito mais do que antes. A outra característica é que a esse número se somam os deportados, os que estão regressando porque... Obama deportou como ninguém. Nenhum presidente deportou tanto como ele. Assim, estão regressando famílias. Já não é o migrante que trabalhou e regressou, adulto, mulheres e homens. O pai é deportado e regressam a esposa com os filhos, tanto os nascidos no México quanto nos EUA. Então, temos o maior fluxo de menores de idade dos EUA. De fato, temos o maior fluxo de migração norte-sul que já existiu. Mais de quatrocentos mil menores de idade que chegaram dos EUA, que nasceram e viveram por lá, estão chegando ao sistema educativo mexicano. De repente, há esse grupo de crianças, cujo principal problema é a entrada na escola em um sistema educativo muito burocrático. Pedem a certidão de nascimento apostilada de lá. Bem, se meu pai é deportado, como posso conseguir a certidão? Isso os impede de entrar na escola. O governo mexicano se flexibilizou e já lhes permite o ingresso. Mas o sistema educativo do México não está preparado para atender crianças que têm uma trajetória distinta. Mesmo que você tenha falado espanhol em casa durante sua vida, isso não quer dizer que você saiba ler e escrever. Há crianças de doze anos que falam espanhol mas escrevem elefante com $p h$, que não sabem nada de História do México, o que representa um problema de integração à escola. [...] Crianças e jovens são estigmatizados, enfrentam discriminação, problemas para transferir o que aprenderam lá. Além da experiência laboral do lado de cá.

Então, temos, aí, um grande desafio: não é o mesmo migrante que ia embora por dois anos, regressava e chegava à casa de sua tia ou avó. Já não conhecem ninguém em suas comunidades de origem por que se foram aos quatro anos de idade. Podem permanecer na fronteira ou em cidades onde há maiores condições de trabalho mas, ainda assim, enfrentam uma série de dificuldades para entrar no mercado de trabalho. O mais interessante é, quando você pergunta aos migrantes aquilo de que eles necessitam, o primeiro que dizem é "uma identificação, algo que me identifique como mexicano". Normalmente, isso significa um título de eleitor. Nesse sentido, o governo mexicano fez uma campanha muito forte. Não sei se vocês, Ernesto e Gabriel, vivenciaram isso com os 
"retornados"8: eles cruzam a ponte 9 e o primeiro que se lhes fornece é um documento de identificação temporário.

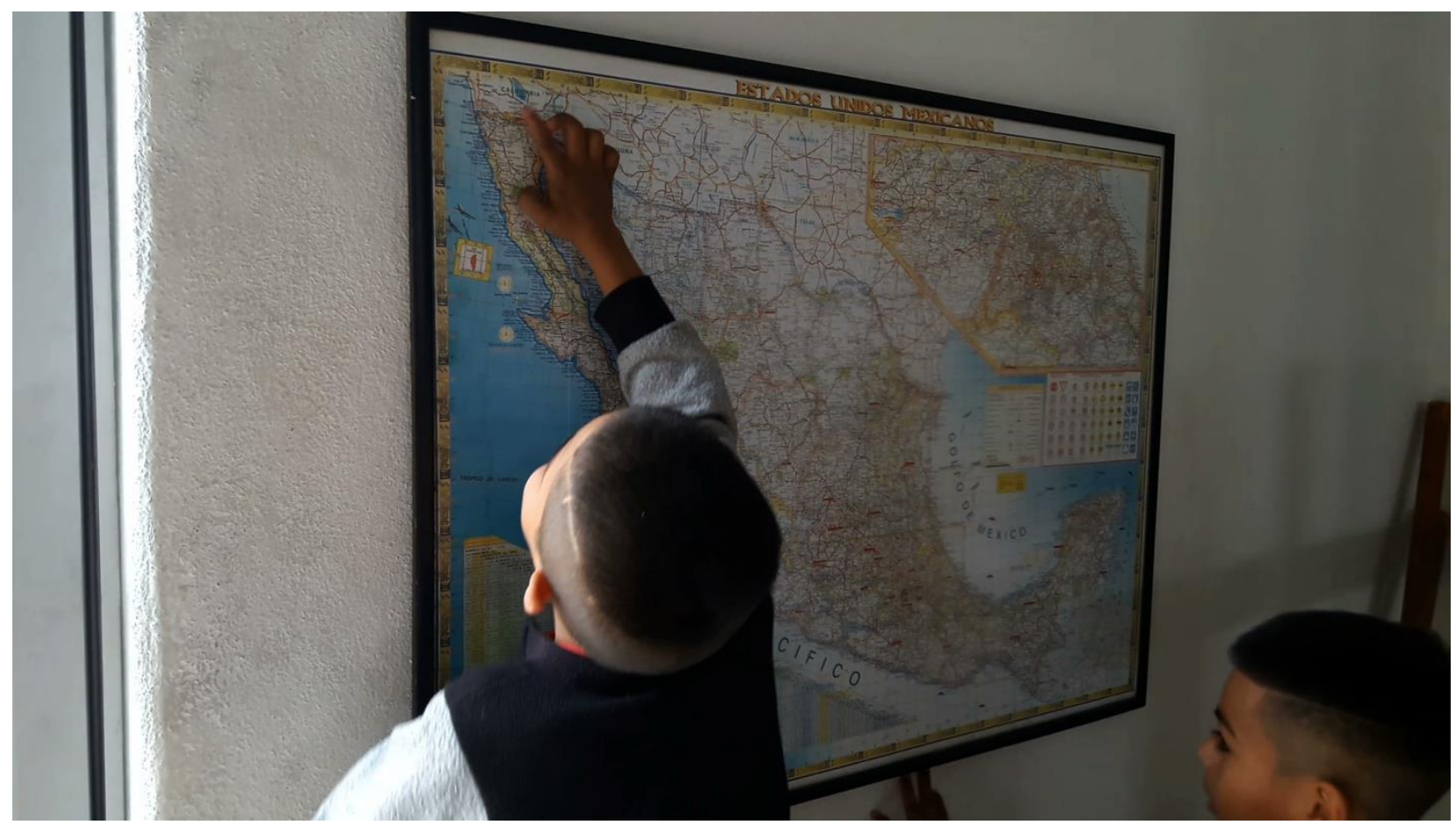

Crianças hondurenhas em trânsito apontam a fronteira México-EUA durante sua estada no albergue Casa del Migrante de San Luis Potosí. Maio de 2017. Foto: Ernesto Morales Bautista/Gabriel Brito Nunes.

E. M. B. - Além de um apoio econômico para viajar até sua localidade de origem...

S. G. - Há muitos programas. O que acontece é que são apoios muito fragmentados. Eles dizem, "nos dão dinheiro para ir a nossos povoados mas, em nossos povoados já não conhecemos ninguém, pra que regressar?”. Eles têm problemas cotidianos. Como não possuem um documento de identificação, não conseguem alugar moradia ou facilitar o acesso de seus filhos às escolas, aos serviços de saúde. Também têm problemas com os bancos, ou seja, não possuem acesso ao setor

\footnotetext{
8 "Retornados", os que retornaram, é a expressão comumente utilizada, no México, para designar os mexicanos - ou filhos de migrantes - que regressaram dos Estados Unidos.

${ }^{9}$ Embora haja várias pontes pelas quais cidadãos mexicanos são repatriados dos Estados Unidos, a mais icônica dentre elas é a Ponte del Paso, uma das três vias fronteiriças terrestres da Ciudad Juárez por onde circulam, diariamente, enormes contingentes de pessoas e mercadorias entre os dois países. Com a mudança de políticas migratórias estadunidenses e a entrada em vigor de tratados internacionais, centro-americanos e pessoas em deslocamento de outras nacionalidades já não podem ser repatriados por essas pontes. Estes são repatriados por via aérea.
} 
Ernesto Morales Bautista

Gabriel Brito Nunes

Lucilene Cury
Cadernos Prolam/USP, v. 17, n. 32, p. 6-18, jan./jun. 2018

DOI: 10.11606/issn.1676-6288.prolam.2018.148830

financeiro. Na verdade, essa gente é bem trabalhadora e cheia de iniciativa. Talvez haja sistemas que lhes permitam capitalizar-se, ter apoio ao crédito, facilitar a transferência de educação e experiência de lá para cá para que eles sejam reconhecidos no México. Eu acho que é, sim, possível fazer algo nesse sentido.

L. C. - A senhora vê uma solução para a crise migratória atual, uma mudança possível, algo além dos muros, ou uma perspectiva de migração ideal? No Brasil, por exemplo, existe o problema da falta de infraestrutura que possa acolher os Venezuelanos que cruzam a fronteira ao norte do país. A questão da fronteira representa, para mim, uma tal barbárie que eu me senti compelida a mudar minha linha de pesquisa para tratar desse tema.

G. B. N. - E, se a senhora nos permite agregar a essa pergunta uma discussão que nos parece urgente, há alguma perspectiva de se trabalhar junto aos planos governamentais apresentados pelos candidatos das eleições em curso, no México?

S. G. - Internacionalmente, creio que seja uma época muito desfavorável para a gestão responsável por uma migração compartilhada. Qual seria o objetivo da migração em geral? A migração não vai parar. O ser humano migra desde suas origens. As demandas dos mercados de trabalho seguirão. As razões para a migração estão aí. Não há como imaginar que possa haver uma mudança rápida para El Salvador, Guatemala, Honduras. As razões para a migração estão postas aí. No caso de países como EUA e Canadá, o processo de envelhecimento fará com que se necessite mais mão de obra imigrante. Então, pode-se supor que esse horizonte vai perdurar: há muitas coisas que nos permitem prever que a migração continuará existindo.

E qual é o cenário ideal da migração? Bem, que ela se dê de maneira ordenada, segura. Que haja convênios entre os países para que ela seja documentada e aconteça dentro dessa ideia de responsabilidade compartilhada. No processo migratório, a responsabilidade diz respeito tanto ao país de saída como ao de entrada. Esse seria o objetivo, se esse fosse o ideal. Você me pergunta como vejo a perspectiva em termos ideias - negra. Por que, considerando o governo de Trump, ou do presidente da Hungria, ou o novo governo da Itália, ou a emergência das direitas em alguns países europeus, o que se revela é um panorama muito adverso onde a migração se torna - no México temos essa expressão - um chivo expiatorio (bode expiatório). Então, assim como 
Ernesto Morales Bautista

Gabriel Brito Nunes

Lucilene Cury
Cadernos Prolam/USP, v. 17, n. 32, p. 6-18, jan./jun. 2018

DOI: 10.11606/issn.1676-6288.prolam.2018.148830

aconteceu nos EUA: quem é culpado pela falta de trabalho? - os migrantes; que o salário mínimo se mantenha baixo? - os migrantes; dos crimes nos bairros? - os migrantes. Cria-se essa polarização em que os migrantes são culpados de tudo. Nesse cenário, é muito difícil mover-nos em direção a um contexto de mais tolerância, de mais abertura à migração, de maior mobilidade. Então, eu creio que, sim, não é um panorama que anime muito em relação ao que estar por vir. Por outro lado, há experiências boas como a sul-americana com o convênio de mobilidade que, claro, entra em tensão com outras coisas como o que está passando com a migração venezuelana no Brasil e em outros países. Há países que têm políticas de asilo e refúgio mais abertas como o Canadá, ou a própria Alemanha, ainda que com todo o custo com que teve de que arcar Merkel. Então, há, por um lado essas experiências.

Agora, o que acho que vai acontecer no México? México tem esse problema - regressamos à esquizofrenia - de muita discriminação ao migrante e não só ao migrante centro-americano, também àquele que regressa. Isso faz com que o cenário seja pouco animador em termos da busca por um horizonte mais positivo para a migração. Além disso, há a pressão estadunidense para que - assim como a Turquia para a Europa - o México se converta no filtro da migração que chega aos EUA.

L. C. - Quão provável é que isso aconteça?

Penso que o México, de repente, queira negociar com o NAFTA ${ }^{10}$ e diga "OK, me deem melhores condições comerciais e eu aumento as restrições na fronteira". Espero que não. Espero que isso não aconteça. Mas é algo que está aí.

E. M. B. - Há medidas que levam a crer que esse cenário não seja tão fíctício. Tomemos o exemplo do Programa Frontera Sur ${ }^{11}$.

\footnotetext{
10 Tratado Norte-Americano de Livre Comércio.

11 Após o que Barack Obama chamou de uma crise humanitária na fronteira sul dos EUA, o governo do presidente do México, Enrique Peña Nieto, implementou, em 2014, o Programa Frontera Sur. Anunciado como uma medida para ordenar os fluxos migratórios e garantir a integridade e o respeito dos Direitos Humanos dos migrantes, esse programa resultou na deportação de milhares de migrantes centro-americanos, dentre eles mais de cinco mil menores não acompanhados.
} 


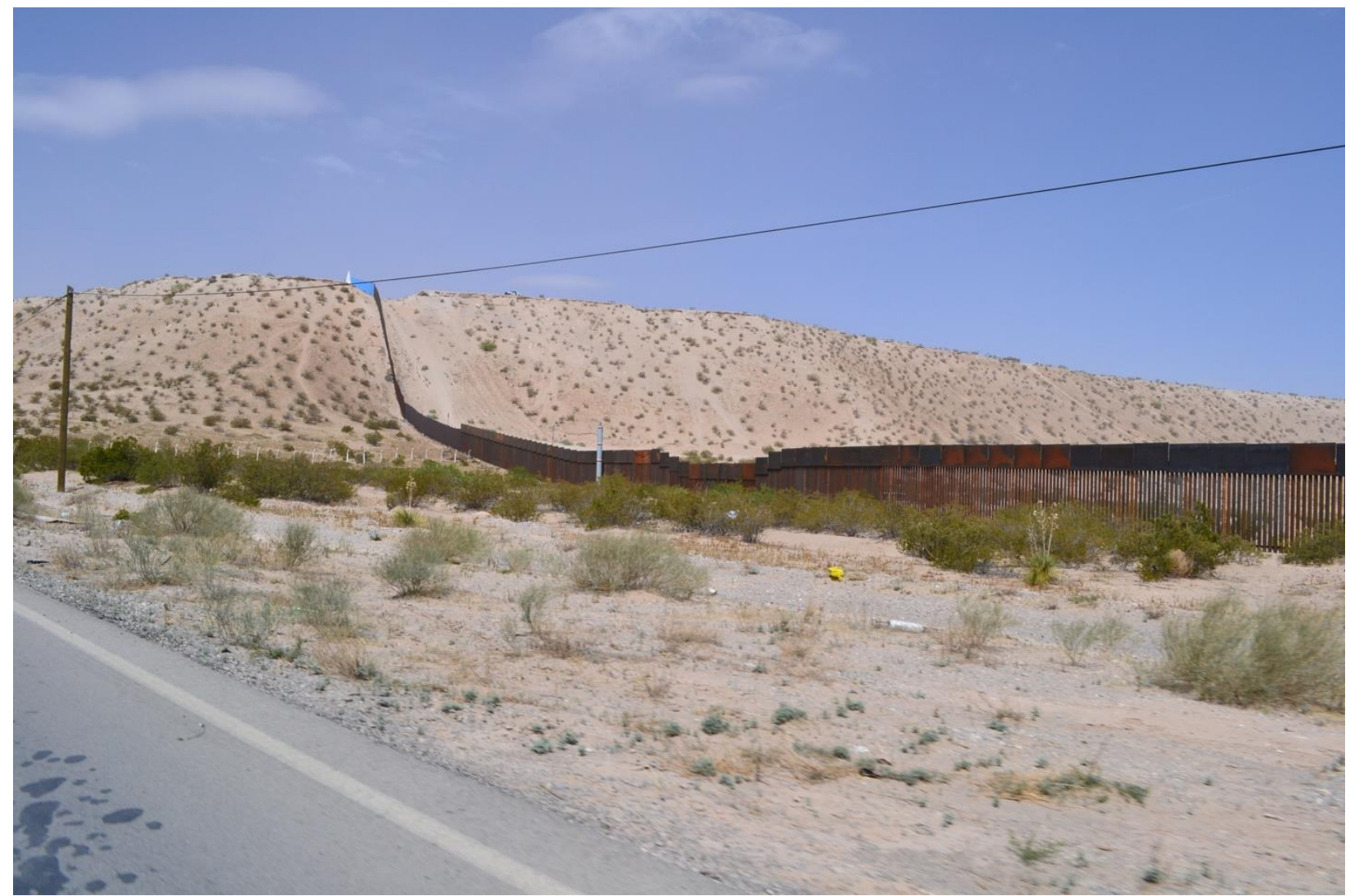

Imagem do cercado fronteiriço no bairro de Anapra, na Ciudad Juárez, uma das rotas de cruze utilizadas pelos migrantes que tentam alcançar o sonho americano. Abril de 2017. Foto: Ernesto Morales Bautista/Gabriel Brito Nunes.

S. G. - Como mencionei antes, é muito contraditório por que fazem uma lei fundamentada na abordagem dos Direitos Humanos e, ao mesmo tempo, fazem o Programa Frontera Sur. É pouco congruente. As instituições responsáveis pelo tema migratório têm muitas denúncias por violação aos Direitos Humanos, recomendações da Comisión Nacional de los Derechos Humanos (CNDH) no México, e eu vejo pouca mudança. Há uma inércia administrativa que não sabem como modificar.

G. B. N. - Essas violações aos Direitos Humanos parecem acompanhar aquelas que forçam populações inteiras de comunidades indígenas a se deslocar, como o recente caso no estado de Guerrero.

S. G. - Sim, uma das diferenças entre o que sucede hoje e o que ocorria há quinze anos é o cruzamento da migração interna com a internacional no que diz respeito ao tema da violência. Quinze anos atrás, falávamos basicamente de uma migração por razões econômicas, familiares, 
Ernesto Morales Bautista

Gabriel Brito Nunes

Lucilene Cury
Cadernos Prolam/USP, v. 17, n. 32, p. 6-18, jan./jun. 2018

DOI: 10.11606/issn.1676-6288.prolam.2018.148830

educacionais. Hoje, há uma série de migrações que responde a uma situação de violência no México, onde a migração interna, em termos de volume, é maior que a internacional.

L. C. - Ainda assim, existe algo de único no processo migratório da relação México-EUA.

S. G. - Para mim, o que me alegra nessa relação, volto a dizer, é essa ideia da população que compartilhamos. Essas crianças que estão chegando ao México e que são cidadãos estadunidenses, quando completarem dezoito anos, escolherão onde viver. Eles poderão votar nos dois países. Como meu filho uma vez me perguntou: “Então, eu posso ser presidente dos dois países?”. “Sim”, eu respondi.

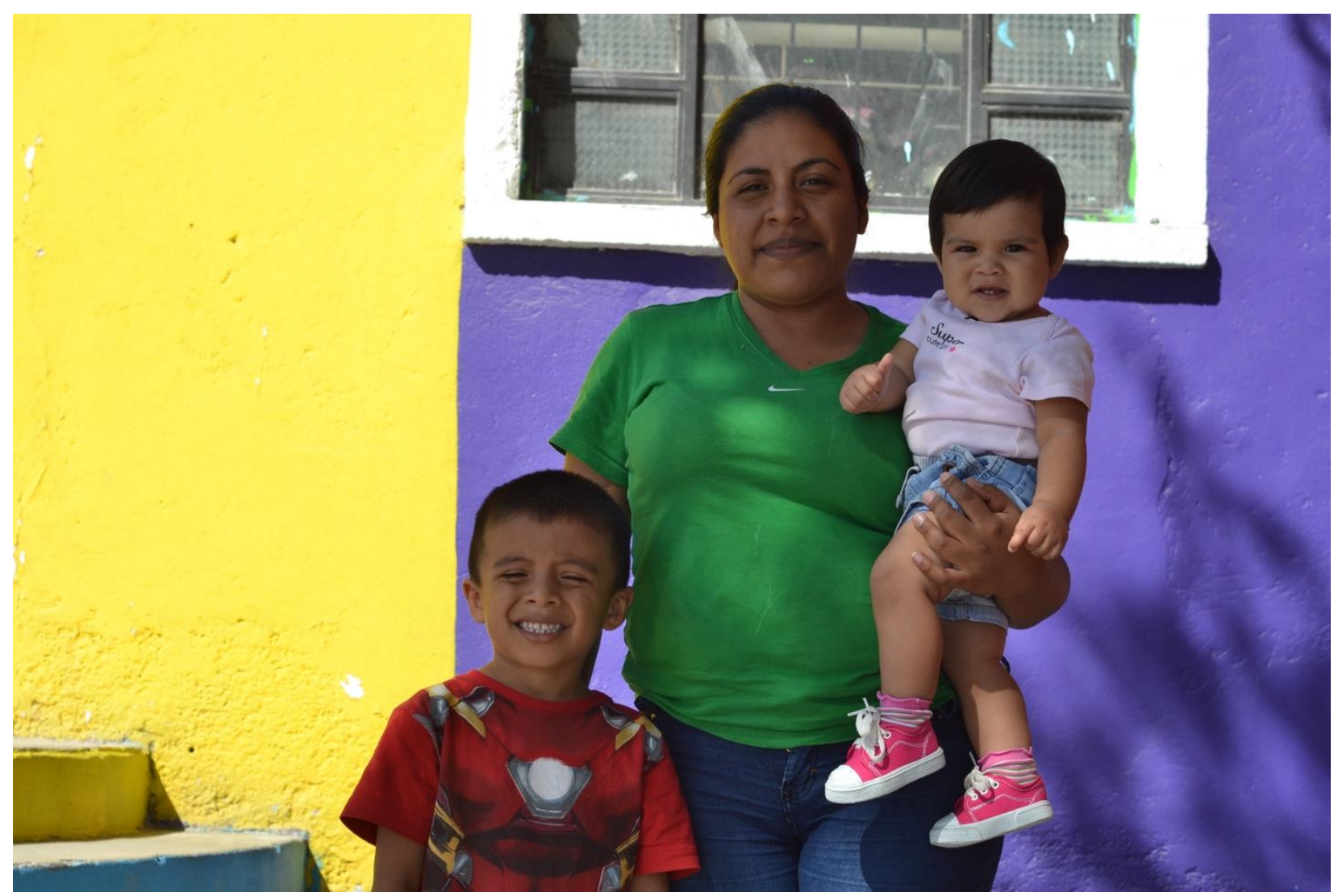

Família salvadorenha em estada na Casa del Migrante de Saltillo a espera de uma resposta a seu pedido de asilo à Comisión Mexicana de Ayuda a Refugiados, COMAR, do estado de Coahuila, no norte do México. Abril de 2017. Foto: Ernesto Morales Bautista/Gabriel Brito Nunes.

Recebido em 09/08/2018. Aceito em 23/08/2018. Publicado em 28/08/2018. 